\title{
A Study of the Electronic Social Commerce Model as Based on Campus Witkey Networks
}

\author{
Qiongwei Ye ${ }^{1}$, Qian Zhang ${ }^{2}$, Nangai Yang ${ }^{3 *}$, Yumei Luo ${ }^{4}$, \\ ${ }^{1}$ Tsinghua University, Beijing, China, 100081, and Business School of Yunnan University of \\ Finance and Economics, 237 Longquan Rd. Kunming, Yunnan China 650221, \\ yeqiongwei@163.com; \\ ${ }^{2}$ Doctoral candidate, International Business Administration School of Shanghai University of \\ Finance and Economics, Shanghai, China; \\ ${ }^{3}$ Business School of Yunnan University of Finance and Economics, 237 Longquan Rd. Kunming, \\ Yunnan, China 650221, \\ ${ }^{4}$ Yunnan University, Kunming, Yunnan, China, 650091
}

Keywords: social commerce, campus Witkey, Spring MVC, Hibernate, Freemarker

Abstract: Thanks to the popularity of internet plus and the rapid development of social networks, the Witkey model has become an important element of the electronic social commerce that meets the multi-level and multi-dimensional needs of people by a full integration of the $\mathrm{O} 2 \mathrm{O}$ model and the SoLoMo model. Through its social service, the Witkey model meets the transactional demands of suppliers and demanders for knowledge, original ideas, and personalized items. However, Witkey generally serves the ordinary customer and is not strong in supporting specific user segments. Campus Witkey networks, on the other hand, are customized online platforms specifically designed for enrolled college students. It is a typical application of the O2O operational model. This thesis constitutes an exposition of the operational and technical model of campus Witkey networks from the theoretical and technological perspective of social commerce. It is also a theoretical extension of the social commerce theory and the strengthening of the important role of social networks in meeting individual needs of people. In this thesis, Spring MVC and Hibernate JavaEE are utilized to construct the platform.

\section{Introduction}

Directed by such national policies as internet plus, industry 4.0 and reform of the supply side as accompanied by the improvement of people's standard of living, new and more diversified needs have emerged, as have new online interactive business models with potential that center round web 2.0. Against this background, social commerce encompasses all the functions that the SoLoMo mode, $\mathrm{O} 2 \mathrm{O}$ and business intelligence possess that satisfy businesses' need for development and people' need for steady improvement of their living standard in the new era. At the same time, diversified needs of customers and the need to spread the brand name of products and enhance customers' trust in businesses have led to the rapid growth and development of social commerce. The Witkey model is a typical example of social commerce that provides various online content service transactions. As a social commerce platform, it is designed to satisfy both the suppliers' and the demanders' needs for knowledge, original ideas, design, and customized products via the internet or social networks that explore new sources of profits for businesses. 


\section{Related Concepts and Their Theoretical Evolution}

\section{Mode of Social Commerce}

Definition of the Mode of Social Commerce. The popularity of the social network has spurred the development of social commerce (Liang, Ho and Li, 2011). Social commerce is a business model that uses web 2.0 (that encompasses customer generated content and sharing) to understand the needs of users and increase the success rate. It uses social network, SNS, blog, social media and network media to aid the buy and sell of goods by way of social interaction and customer generated content. Social commerce is a subdivision of e-commerce. It enhances individuals' shopping experience by utilizing social media for the support of social interaction. For product users, social commerce does enhance their shopping experience and their recognition of products starting from "need recognition", product discovery, choosing of products to reference products. The characteristic infiltrating relationship style of social commerce has advantages over the broadcasting style of traditional business model. According to Yanfei Ju (2012), social commerce is characterized by such traits as passive consumer needs, the influence and change of shopping behavior and the participation of users in generating business information.

Categories of Social Commerce Models. Social commerce involves interactions designed to enhance users' recognition of products before, during and after the sale in the social network environment (M. S. Yadav etc., 2013). There are five mainstream social business models. Customer flow induction model is the first model. It gains commission income by proactively directing the customer flow to the electronic business platform and assisting the business to achieve higher conversion rates. The second model is the open platform model. It is constructed by the social media and uses third party apps or add-ons to increase user activity and loyalty as well as to increase the flow to the website. The third model is the flow realization model. A social commerce business builds its own independent e-business platform and uses it as a flow realization mechanism, like Icson as supported by Tencent. Publicity and promotion is the fourth model. For this model, ecommerce appears in the form of brand promotion and enhancement via social media, but it is not in the design to directly facilitate e-business transactions just like Suning and Skyline community. The last is the information sharing model. It refers to a social presence on the social media where clients exchange product information and produce customer-generated ads in a controlled environment. Social commerce is the combination of social media and electronic commerce, and the success of a business model depends on the maximization of the shared interests of the two. Through social platforms, businesses establish and maintain good relationship with clients, provide differentiated goods and customized services so as to maintain comparatively high level customer loyalty and good profit margin that is sustainable in the long term.

Birth of the Witkey Model. In today's experience economy era, the internet has become the carrier of information and knowledge, and people are getting increasingly dependent on information. This has led to the booming of internet-based platforms that integrate knowledge. Wechat's circle of friends, Baidu Post Bar and Sina Micro-Blog all indicate the arrival of the web 2.0 era with SNS as its label. Information sharing has gradually moved from a static state to a dynamic state and users have turned from information receivers into information generators and carriers just like in Zhihu. From this we can see that the success of a business model relies on the full use of its information diffusion advantages (Centela, 2010) of social networks to increase viscosity of users and give knowledge infinite value. Witkey was first used by the Chinese scholar Liu Feng in 2005. It refers to people who turn their wisdom, knowledge, capabilities and experience into realistic gains via the 
internet. They get paid for solving scientific and technological problems both at work and in life over the internet which led to the creation of the new model. Because of the attention the Witkey model has received in theoretical studies and the media, it has become more widely accepted. In 2006, the term Witkey had become the synonym of the new electronic business model and began to quickly spread over the internet. By 2007, the word Witkey appeared among the 171 new words as published by China's Department of Education. This indicated the acceptance of the new model by society. Iresearch statistics from the 2010 Witkey conference showed that there were over 100 Witkey websites in China with more than 20 million registered members. The total amount of transaction exceeded 300 million RMB yuan and five of the websites had an accumulated transaction volume of over millions of RMB yuan. And this was just the beginning stage of Witkey development (Baidu Baike, 2016).

The Witkey Model and Its Aanalysis. In English, Witkey is the combination of wit and key which means the key to wisdom. Hongliu et al (2008) believes that the Witkey model is a generic term for all interactive question and answer websites. They defined it as a model, a C2C model for the user to use the interactive question and answer platform over the internet to realize the value or the economic value of wisdom, knowledge and skills. It differs from the traditional $\mathrm{C} 2 \mathrm{C}$ model in that it is the combination of the platform operation model and the information sharing platform in social commerce. It deals with intangible assets, namely providing services. The Witkey model involves three parties: the servicer of Witkey (also referred to hereafter as the platform party), the party with needs (Those who use the Witkey platform to ask questions and get answers to their questions), and the servicer (That is, the witkeys or people who have the knowledge or experience to answer the questions from those with needs). What connects those with needs and the witkeys is a well-constructed platform. Similar to a two-way market (1) (Armstrong, 2006), the Witkey model grows by bridging the information gap between those who need information and the information providers and by making use of social networks and customized marketing methods.

As a new business model, the Witkey model encompasses six operating models which are positioning, business system, key resource capacity, profit model, free cash flow structure and company value tradition. The Witkey business model is as shown in chart 1 . Positioning is the starting point of all business activities as well as the key to success. Positioning decides what product or service a business intends to provide to satisfy customer needs and realize customer value. There is plenty of literature and theoretical study of positioning. Porter and Cantela tried to define positioning from different perspectives. In his Competitive Strategy, Porter approached it from the strategic perspective. He believes that positioning involves a series of decision making regarding the development of a business. On the other hand, Cantela defines positioning from the implementation perspective. He believes that positioning means a series of activities in relation to the determination of product features and pricing. According to Baidu Wenku, Business system includes business links needed for business positioning, the roles business partners play and the manner and content of cooperation or transaction of stakeholders. It may be considered as the daily operation of a business. Key resource capacity refers all related resources needed for the completion of daily business operations. Profit model refers to the method a company uses to make its profits. A good profit model not only brings the business long-term profits but constructs a stable and winwin value system for the business. The free cash flow structure looks at the cash income of a business and its condition after the deduction of cash investment. Business value is synonymous to the ultimate investment value of a business. It is the end goal of a business model since a good 
business model needs to be able to increase the value of a business. To sum up, business positioning determines its business system, resource allocation and profit model and structure which in turn determines its free cash flow structure. A good cash flow structure increases the value of a business. When the business value is not going up, it is necessary to figure out which business link is not functioning and whether the business needs to adjust its positioning.

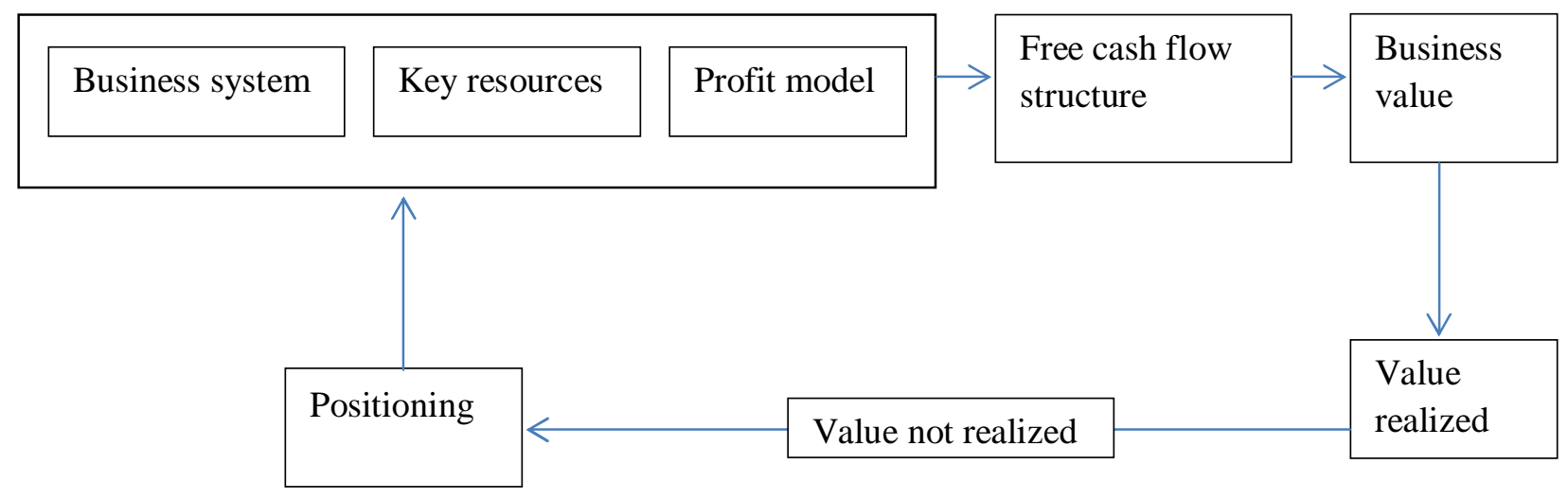

Chart 1 Structure of the Witkey Model

Characteristics of the Witkey Model and Its Classification. Xingxin Liu (2006) divides the Witkey model into three categories. For the first category, all platform users are allowed to help each other with problem solving, data search and information collection. In the second category, whoever raises a question gets to set the price for the question and choose to accept the answer or not or comment on the answer and whoever answers the questions gets to choose which questions to answer and how to answer them. In the third category, all questions and answers from everybody are gathered together to form a huge knowledge database, open to all users and ready to be updated by all the participating users. Xinshi and Xiuyi Zhou (2009) have identified seven characteristics of Witkey. They are informative, interactive, paid, comprehensive, grass roots, individualized and standardized. In fact, the Witkey model could extract such business traits as high information value, powerful positioning, easy access and non-restraint of time and space from social business models, personalized marketing and the SoLoMo model. Chart 2 is a classification of the Witkey websites by their system model and their business model (Yan Zhang, 2006) 


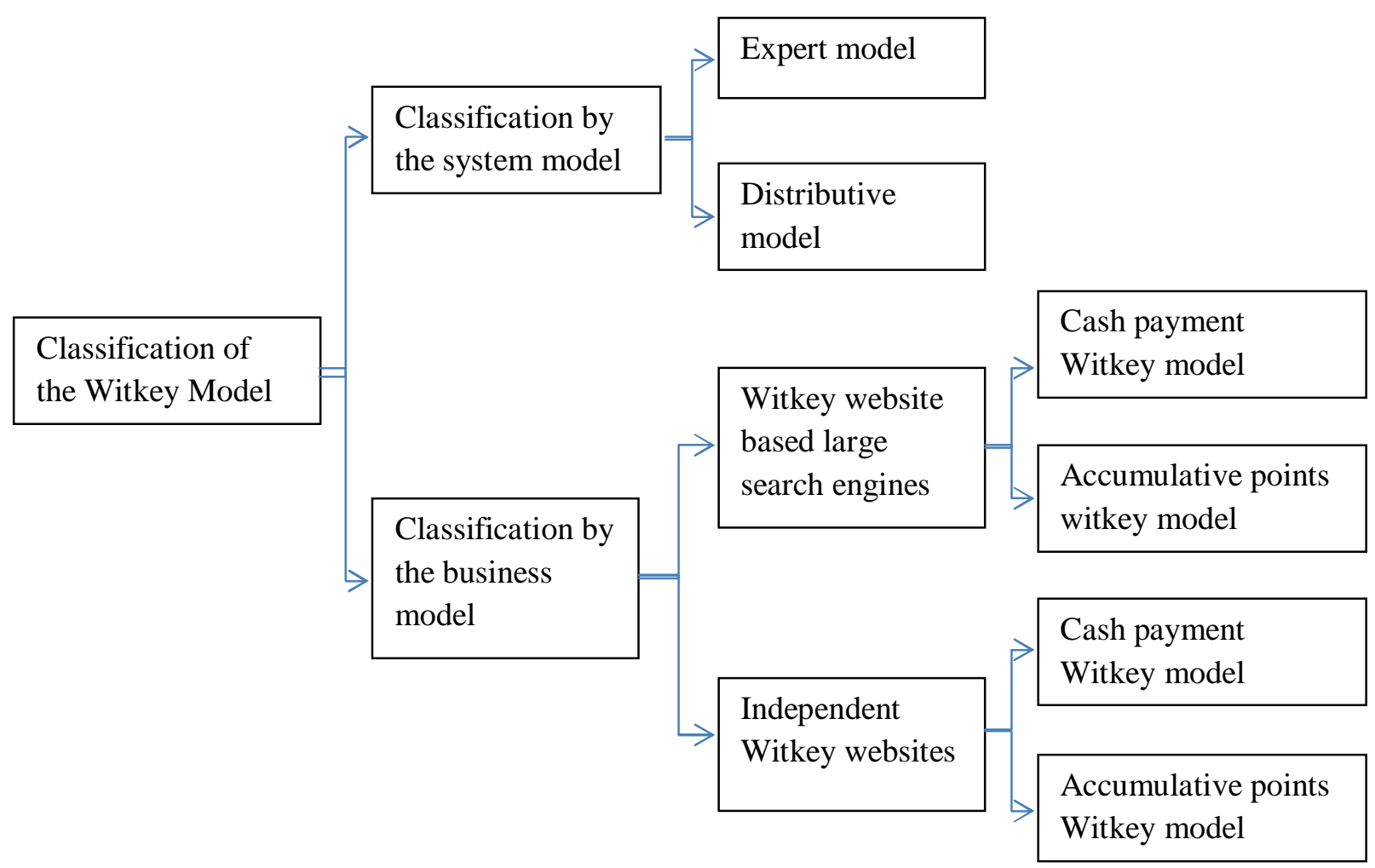

Chart 2 Classification of the Witkey Model

Chenming Zhang (2008) is the first to study the classification of the Witkey model. He classified them as A, B and C. A is the accumulative Witkey who answers some questions or provides suggestions based on the knowledge and skills they have or the experience they have accumulated. $\mathrm{B}$ is the bid for prize Witkey. This individual gets the opportunity to work on a project by bidding for the project and winning it. Thus she/he generates value. Type $\mathrm{C}$ Witkey sells their knowledge and skills by way of displaying, verifying or managing their abilities. This way they turn their abilities into skill products establishing a transactional relationship with corresponding needs. Based on Zhang's classification, Feng Liu (2006) suggested the Map Witkey or M Witkey. This is a search engine for the user that is created by pulling together four most important characteristics of the Witkey such as the geographic location, specialty or interest, contact information and his/her Witkey space. However, secondary characteristics as age, profession and gender may also be included.

Comparison of the Witkey Model with Other E-Commerce Models. The Witkey model is really a $\mathrm{C} 2 \mathrm{C}$ model that provides a platform for business transactions between customers. It differs from the traditional $\mathrm{C} 2 \mathrm{C}$ model in that it is intangible assets like knowledge and experience that are traded on this platform. Table 1 shows the differences and commonalities between the Witkey model and other new e-commerce models such as blog, crowd-funding, online group shopping and search engines. 
Table 1 A Comparison of the Witkey Model and Other New E-Commerce Models

\begin{tabular}{|c|c|c|}
\hline Name & Commonalities & Differences \\
\hline Blog & $\begin{array}{l}\text { Derived from the BBS model with } \\
\text { such functions as information } \\
\text { publishing, needs statement and } \\
\text { interaction }\end{array}$ & $\begin{array}{l}\text { Profit model more generic, with } \\
\text { most of the income coming from } \\
\text { ad sponsors }\end{array}$ \\
\hline Crowd-funding & $\begin{array}{l}\text { Facilitated by the online platform } \\
\text { that involves two parties }\end{array}$ & $\begin{array}{l}\text { New channel of fund raising with } \\
\text { money raised via } \mathrm{P} 2 \mathrm{P} \text { and } \mathrm{P} 2 \mathrm{~B}\end{array}$ \\
\hline Online group shopping & $\begin{array}{l}\text { Susceptible to influences beyond } \\
\text { the internet, has online and offline } \\
\text { models }\end{array}$ & Sells products or service \\
\hline Search engines & $\begin{array}{l}\text { Resource sharing by way of } \\
\text { integrating information }\end{array}$ & $\begin{array}{l}\text { Insufficient interaction, poor } \\
\text { service targeting, profit model } \\
\text { dependent on ad bidding and } \\
\text { bidding for the listing of search } \\
\text { results }\end{array}$ \\
\hline Crowdsourcing & $\begin{array}{l}\text { Reassign the project to others for a } \\
\text { fee }\end{array}$ & $\begin{array}{l}\text { Outsourced to teams rather than } \\
\text { individuals as in the Witkey model }\end{array}$ \\
\hline
\end{tabular}

\section{Social Commerce Services Provided by Campus Witkey Networks}

Analysis of the Campus Witkey Business Model. The analysis will be done using important components from Alexander Osterwalder and Yves Pigneur's description of business models in combination with some campus Witkey cases. The components are market positioning, market segments, operating models, profit models and expanding models. Chart 3 reveals the business model of campus Witkey platforms.

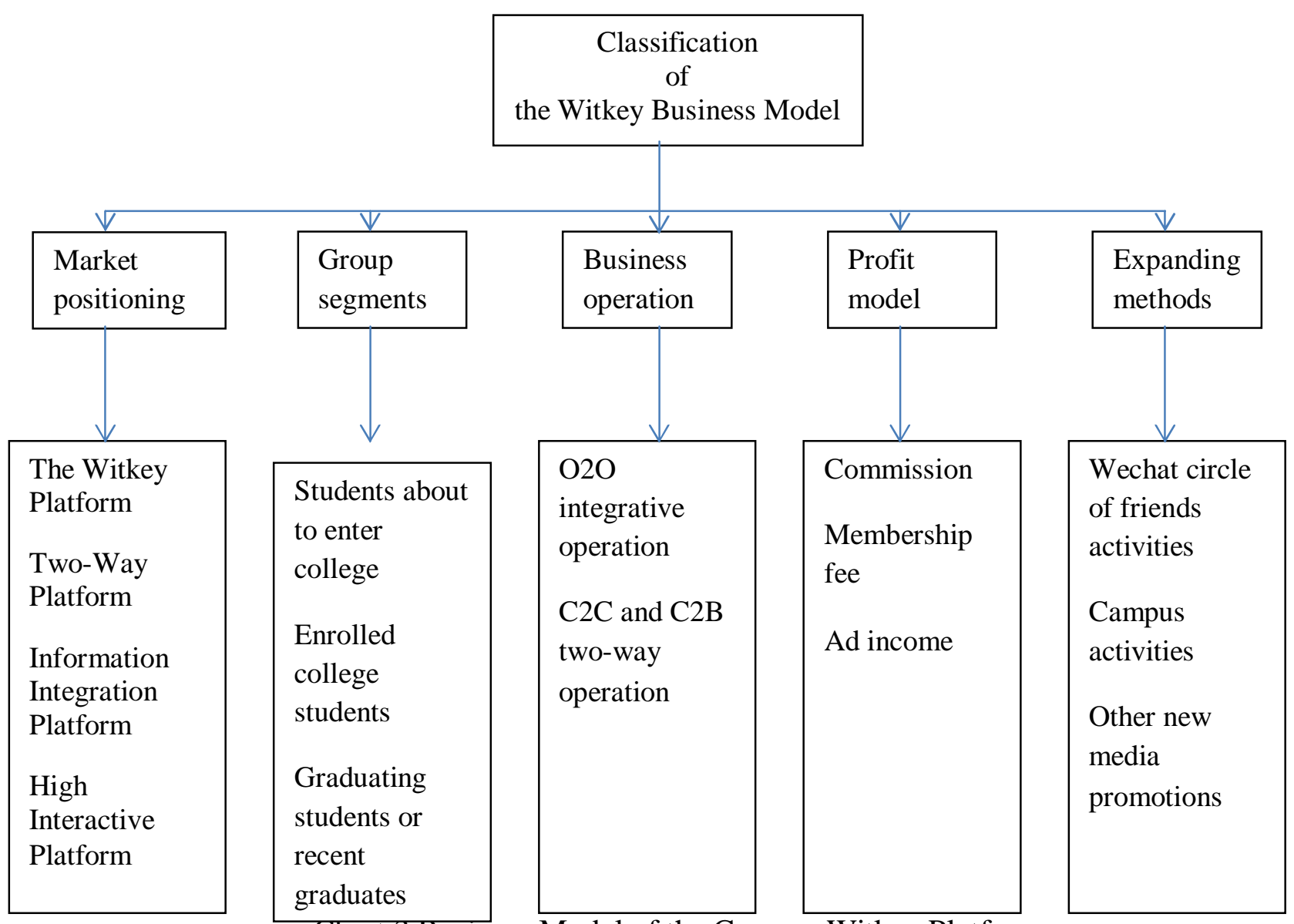

Chart 3 Business Model of the Campus Witkey Platform 
The campus Witkey platform is an open third party assistance platform independent of the two parties involved in the transaction. Suppliers and demanders are attracted to the platform to publish their supplier or demander information. But the platform provider does not participate in the transactions. The decision to transact or not is up to the supplier and the demander's judgment with no assistance whatsoever from the platform provider. The website charges a certain percentage of the transaction amount when transactions are successful. To ensure the interests of the service supplier, the demander needs to deposit a relevant amount of fund with the platform so that the fund can be transferred to the supplier when the transaction is successful. Before the fund is transferred, the platform could deposit the money with servicers such as Yuebao to generate stable daily income. The platform also provides the priority option for the supplier or demander. When a certain amount of a fee is paid, the supplier or the demander's information will appear in the designated position of the first page for more people to see. Later, when the same side network effect increases the flow volume on the platform or when the cross boundary network effect of the platform happens, more businesses are attracted to the platform to post their ads(2).

Market Positioning. Market positioning is the most important link of a business model, the starting point of all business activities that is a choice of the business' marketing strategy. There are three types of marketing strategy, namely, the non-differentiated strategy, the differentiated strategy and the centralized marketing strategy. The non-differentiated strategy views the entire market as one big target that is not segmented where the same product and the marketing mix is applied. The differentiated marketing strategy divides the entire market into a number of segments where needs and expectations generally converge. Then given the resources and their marketing power, an enterprise is able to decide on a different marketing mix for its segment markets. The centralized marketing strategy targets only one or a limited number of segment markets and decides on a corresponding marketing mix for centralized marketing after dividing the entire market into segments. After comparing the above mentioned three strategies and the reality they face, the campus Witkey platform tends to use the centralized marketing strategy. Whether we use the two market classification criteria delineated above, or given the fact that campus Witkey platform builders are usually enrolled college students who understand the needs of their fellow college students, college students are the natural target of campus Witkey platforms.

Because of the fact that most current Witkey services target the general user, the support for segment users is very limited. Hence campus Witkey platforms position themselves as a big platform designed to accommodate the various needs of college students. By segmenting the increasing needs category of the student users, campus Witkey platforms apply the extreme and precision service standards to satisfy the group's needs for efficiency, safety, cost performance and individuality.

Market Segmentation. College students belong to a very stable group that possesses high label attributes. They are both creators and consumers of such good content as knowledge and original ideals. Therefore, they are very a good target group for Witkey websites. Given the distinctive labels associated with college students, it is not difficult to classify their needs by their hobbies, area of specialty and phase of study. The objective is to provide highly personalized services or heuristic services to increase students' interest level, strengthen the value relationship among users and expand the size of the market. Chart 4 divides the different needs of students at different stages into the following three categories: 


\begin{tabular}{|l|l|l|l|}
\cline { 2 - 4 } \multicolumn{1}{c|}{} & Characteristics & Major Needs & $\begin{array}{l}\text { Major Source of } \\
\text { Information }\end{array}$ \\
\hline $\begin{array}{l}\text { Students About to } \\
\text { Enter College }\end{array}$ & $\begin{array}{l}\text { Full of expectations } \\
\text { for college life }\end{array}$ & $\begin{array}{l}\text { To know more } \\
\text { predecessors }\end{array}$ & Post bar \\
\hline $\begin{array}{l}\text { Enrolled College } \\
\text { Students }\end{array}$ & $\begin{array}{l}\text { Limited } \\
\text { communication }\end{array}$ & $\begin{array}{l}\text { Social, entertainment } \\
\text { and study }\end{array}$ & $\begin{array}{l}\text { Wechat and Tianya } \\
\text { Community }\end{array}$ \\
\hline $\begin{array}{l}\text { Graduating Students } \\
\text { or Recent College } \\
\text { Graduates }\end{array}$ & $\begin{array}{l}\text { About to enter the } \\
\text { next phase of life }\end{array}$ & $\begin{array}{l}\text { Education, life and } \\
\text { work }\end{array}$ & $\begin{array}{l}\text { Forum, Soufun, } \\
\text { Website for new } \\
\text { graduates }\end{array}$ \\
\hline
\end{tabular}

\section{Chart 4 Information to Be Recommended to Different Users}

Business Operation Flow. Chart 5 is a demonstration of the campus Witkey platform's business flow structure. Major functions of the platform are user registration and login, publishing needs, publishing service, registering needs, making an appointment, searching related needs service, user's personal center and paging display. Below is a chart of the major functions of the platform's major business flow and its logic:

(2) Same side network effect means that when the size of one market group users goes up, it will impact the effect all other users in the group get while the cross-boundary network effect means that the increased number of one group of users will impact the effect another group has when using the platform.

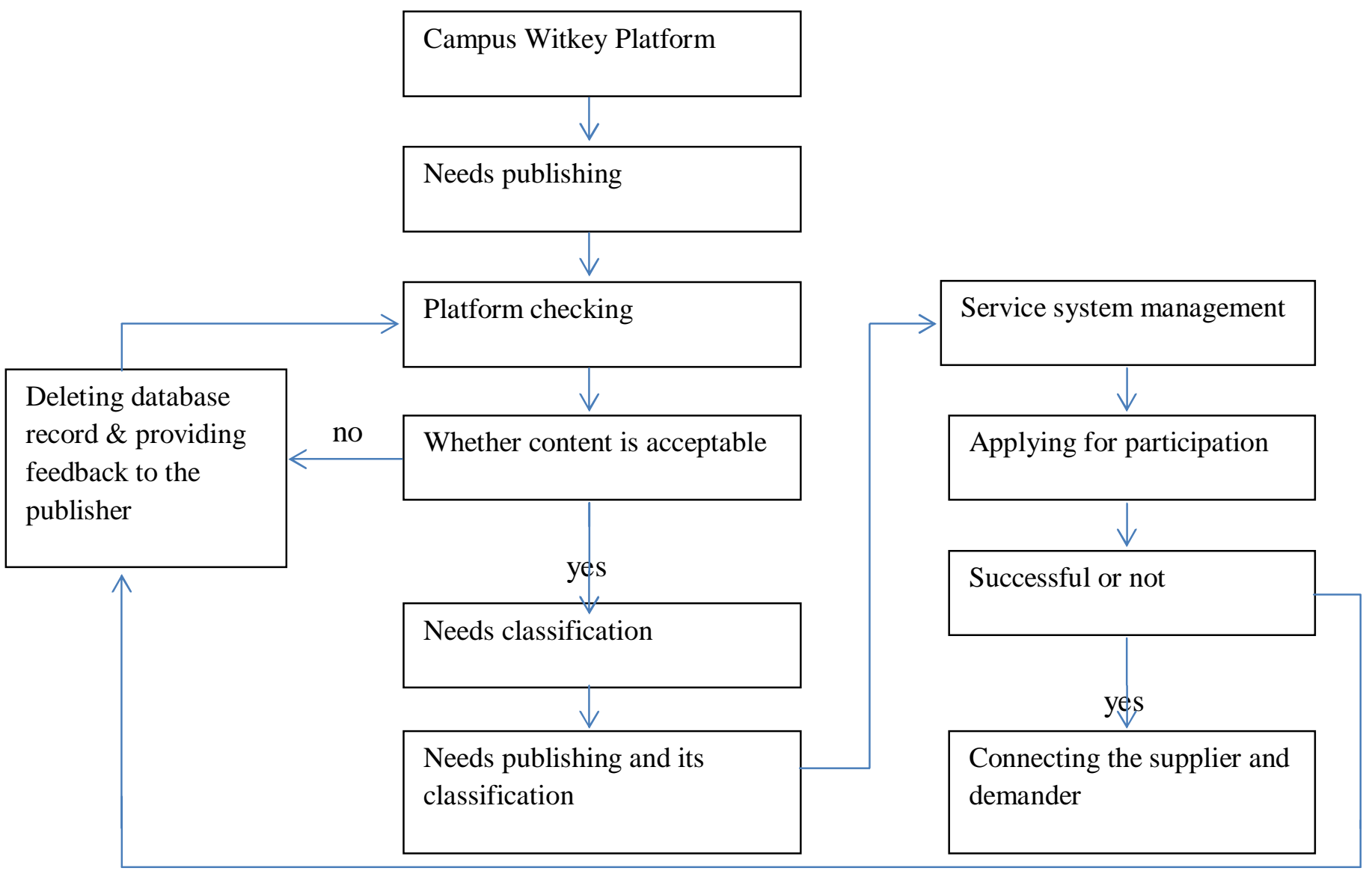

Chart 5 Key Business Flow Chart

Profit Model. There are two phases to the profit model. The first phase is a free period when super scholars are attracted to share their experiences, influential students to publish information or brats from all majors to station on the platform, and some training organizations are also invited to 
participate. The second is the fee phase charged in the form of commission, membership fees and ad fees.

Platform Promotion Strategy. Now is the internet era when information travels very rapidly. Hence it is necessary for Witkey websites to be marketed to the destination target as soon as most of its functions are ready. And corresponding bugs can be patched or appropriate strategic adjustment be constantly made in a timely fashion in response to the trial use or feedback from users. This instant adjustment is an attempt to respond to the fast and iterative evolution that is internet thinking, just like what Kevin Kelly stated in Out of Control that whoever gets a flexible external format gets paid, and that this is the essence of evolution.

Technological Realization Plan for Campus Witkey Networks. The Witkey website's basic functions are realized by using the Java B/S Spring MVC framework together with the Hibernate data persistence technology. The global index search and key word search functions for task related data on the other hand are achieved via the Lucene framework. And the user label summary is done using personal information provided by the user. Finally personalized and task related needs recommendations are made via the application of collaborative filtering and the relevance rule. Below is a detailed explanation of the technologies used.

The Spring MVC Framework. The MVC or Model-View-Controller model is an organizing format for software systems. Chart 8 is a diagram of the MVC's organizational relationship where $\mathrm{M}$ is the data model, $\mathrm{V}$ is the user interface and $\mathrm{C}$ is the controller. The purpose of using a MVC is to decouple $\mathrm{M}$ and $\mathrm{V}$ so that the same program could be used to achieve multiple presentations for better code reuse. The use of $\mathrm{C}$ is to ensure the synchronization of $\mathrm{M}$ and $\mathrm{V}$, which means that when $\mathrm{M}$ changes, $\mathrm{V}$ is automatically updated.

Spring is a light-weight container frame for inversion of control and aspect-oriented programming. Spring MVC is a MVC model solution for the more complex B/S development environment contributed by the Spring development team. Basic steps are that the DispatcherServlet receives a user's request via the browser, invokes a corresponding handler in accordance with the request, sends the result from the handler back to the JSP and JSON data formats via the corresponding Model's business logic and data request, and finally sends the file back to the user in the HTML format that is translated by the interpreter and capable of being analyzed by the browser thus completing one circle of user interaction.

Hibernate. Hibernate is the ORM or Object-Relationship Mapping frame of an open source code that provides the JDBC with a very lightweight object packaging thus giving the developers complete freedom to monitor the database by way of AoP technology. Not only does this provide a mapping of Java and tables from the database, but it also creates a data query and recovery mechanism. Compared to the manual monitoring of the database using JDBC and SQL, Hibernate has greatly reduced the workload associated with database programming.

Freemarker. Freemarker is a model engine written in the Java language that produces text output using a model. It has no relationship with web containers because it is unaware of the existence of Servlet or HTTP when the web is running. Freemarker can be used not only for the technological realization of the presentation layer, but for the making of XML, JSP or Java source codes. 
The principle of the Freemarker is that a model plus a data model equals output. The model is solely responsible for the presentation of data in the pages. It does not involve any logic codes that are all handled by the data model. What the user ultimately sees is the combined creation of the model and the data model.

JavaScript. JavaScript is a customer end script language driven by an object or event often used to add various dynamic functions to the webpage to give the user a more fluid and comfortable browsing effect. Normally, Java script is inserted in html for its functional realization. For example, JavaScript is used in many places in the Witkey platform. When users publish their needs or services, they use JavaScript to check whether the html forms have the corresponding values. If not, JavaScript reminds them. Another example is the countdown function. It is realized when the backstage Spring MVC sends the deadline of a record to the JavaScript inserted in the frontstage html. However, many more functions that JavaScript can be used to achieve are not to be reiterated here.

DIV+CSS. DIV is the positioning technology used in Cascading Style Sheets. Its components are used to provide structure and background for large chunks of html contents. And CSS is short for Cascading Style Sheets. DIV+CSS is a web design standard, a way for arranging the web pages. Different from the traditional table arrangement, DIV+CSS is capable of separating web content and its presentation on the web pages. An example is the site.css folder for all css files on the Witkey website. When imported into the separate html folder on the top of the website, this css file can be very conveniently used to beautify the webpages.

Use of Personalized Recommendations in Campus Witkey Networks as Based on Big Data. While pushing personalized contents to the user is passive and information publishing and search operations conducted by the user are proactive, both are effective methods platforms currently use to increase platform usage, user viscosity and search efficiency. And their respective goals are to target the needs of both the receiving user and the publishing user and recommend contents or tasks that are valuable or the users are interested in.

In order to recommend customized contents for the user, it is important to set up a relationship between the task provider, the task and the task receiver so that the system could make a model match among the participating parties to reach the maximum effect. Methods that are often used for content recommendations include the relevance rule, synchronization filtering and content filtering. When used collaboratively, these methods could make the best use of various user data and achieve the best recommendation effect possible.

To recommend contents for the user, the first task is to learn about the user and feature of the content to be recommended. Secondly, a relationship needs to be found between the user and the content that can be automatically calculated by a software system. For example, big data analysis and data mining technologies can be applied to the extraction of object characteristics. And the relationship can be calculated using machines and their related learning theories. Now for the case study cited in this paper:

Extracting User Attributes. This system targets the user group of college students who possess distinctive label attributes. They are the class attributes and the after class attributes. The class attributes include such aspects as school, major, curriculum, grade, and past performance. The after class attributes, on the other hand, encompasses aspects as gender, age, hobbies, extra-curriculum 
activities. And every attribute can be further segmented using one to multiple labels. An example is past academic performance which can be the 100 points system for each course or big categories like excellent and good mostly applied to science major students. When user data is gathered and sorted through various channels, we get related attributes tables.

Extracting Task Attributes. Tasks in the Witkey networks contain structured and unstructured data. Structured data include such designer designated segments as the title, body, category, pricing and period. And unstructured data is contained in the specific title and content that has to be mined.

Relationship between the Objects. When a certain amount of user attributes and task attributes data are mined, patterns of regularities may be applied to the large amounts of obtained or yet to be obtained data for model exercises so that the model remembers the matching model between the user and the task. In case new users or new tasks emerge, the system could use the model to connect related objects and complete the recommendation assignment.

\section{Conclusion}

Using the campus Witkey network as an example, this thesis expounded the overall structure of social commerce models as represented by the Witkey model and theoretically demonstrated the great importance of social network users to the success of electronic business platforms. Specifically, the existence of key users in social networks has enabled the Witkey model to aim for more accurate positioning, speed up information spread among users and strengthen brand recognition. On the other hand, the Witkey model has inspired users to become witkeys. This has helped to solidify the important contribution of user generated contents to Witkey networks. The operation of campus Witkey networks has fueled greater curiosity and more interest in new developments among groups of young people. This has led to increased interaction among college students and the added value of information which shows that highly efficient and easy to use technology models are indispensable to both campus Witkey users and a company's success.

\section{Acknowledgements}

This research was supported by the National Natural Science Foundation of China under Grant 71162005, 71362016, 71402159 \& Yunnan Provincial E-Business Innovation and Entrepreneurship Key Laboratory of colleges and universities (YES 2014 [16]).

\section{Reference:}

[1] Damon Centola: Science Vol. 329 (2010), pp. 1194-1197.

[2] Houben, GLenie and KVanhoofK: Decision Support Systems Vol. 02 (1999), pp. 125-135.

[3] Mark Armstrong: RAND Journal of Economics Vol. 10 (2006), pp. 668-691.

[4] Nelson P.: Journal of Political Economy Vol. 02 (1970), pp. 311-329.

[5] Ronald S. Burt. Structural Holes: The Social Structure of Competition. Harvard University Press, 1995.

[6] Shi XCOIM: Library \& Information Vol. (2009). 
[7] Stephen P. Borgatti, Ajay Mehra and Daniel J. Brass et al.: Science Vol. 323 (2009), pp. 892895.

[8] TingPeng Liang, YiTing Ho and YuWen Li, et al.: International Journal of Electronic Commerce Vol. 16 (2011), pp.69-90.

[9] Yadav M S, Valck K D and Hennig-Thurau T, et al.: Journal of Interactive Marketing Vol. 27 (2013), pp. 311-323.

[10]Zhang L., in: 2015 International Conference on Humanities and Social Science Research, Atlantis Press (2015).

[11]Information

on http://www.baike.com/wiki/\%E5\%-A8\%81\%E5\%AE\%A2\%E6\%A8\%A1\%E5\%BC\%8F.Baidu Encyclopedia

[12] Yuanpu Jin: Zhong Guan Cun Vol. 03 (2011), pp.70-75.

[13] Jing Li and Yang Sheng: Journal of Information Vol. 09 (2007), pp. 60-61.

[14]Xiaoshan Lin: China Youth Study Vol. 06 (2007), pp. 5-8.

[15] Information on http://blog.sina.com.cn/s/blog591a83bf010009yn.html

[16]Feng Liu: An Analysis of Witkey's Business Model. Beijing: Graduate School of University of Chinese Academy of Sciences. 2006.

[17]Xingxin Liu: Journal of the National Library of China Vol. 03 (2007), pp. 70-72.

[18]Information on http://market.ccidnet.com/pub/report/show--9858.html

[19] Information on http://wenku.baidu.com/v-iew/f8bcd6a3f524ccbff12184af.html

[20]Nali Shen: A Study on Integrity Management in Electronic Commerce. Chongqing: Chongqing University. 2006.

[21]Xinshi and Yixiu Zhou: Library \& Information Vol. 01 (2009), pp. 69-72.

[22]Caihong Xu: Shangchangxiandaihua Vol. 481 (2006), pp. 94-95.

[23]Information on http://blog.sina.com.cn/s/blog-452fe49f010005b2.html

[24] Yan Zhang: Journal of Sichuan Engineering Technical College Vol. 05 (2006), pp. 29-31. 